\title{
New Low-Speed Testing Device for Skid Resistance of Highways and Airfields
}

\author{
Sen Han, T. F. Fwa, and Mengmei Liu
}

\begin{abstract}
Low speed skid resistance measurement is of great significance to analyse the actual causes of insufficient friction of pavement, and to formulate appropriate maintaining measures. At present, the British Pendulum Tester (BPT) and Dynamic Friction Tester (DFT) are commonly used to measure the lowspeed skid resistance of pavement. However, previous studies have shown that there are operational limitations in the use of BPT and DFT. A new low speed friction tester (WFT) developed by Chang'an University was introduced in this paper. The stability, accuracy and efficiency of BPT, DFT and WFT were compared through laboratory tests and field tests. The influence of test speed on WFT test results in the range of normal walking speed was evaluated. Results show that the stability of WFT test was better than that of BPT and DFT. BPT test results were unreliable and DFT was unsuitable for coarse surfaces or groove surfaces of pavement. WFT is time efficient in testing time, especially in field tests. The study also shows that the test speed had little effect on the WFC at the statistical significance level of $\mathbf{9 5 \%}$. Therefore, WFT can be used as a practical alternative to BPT and DFT, for testing the low-speed friction of pavement in laboratory and field.
\end{abstract}

Index Terms - Road engineering, low-speed skid resistance, British Pendulum Tester, Dynamic Friction Tester, Walking Friction Tester.

\section{INTRODUCTION}

$\mathbf{S}$ kid resistance is considered to be one of the most important characteristics of pavement, and has become a matter of immediate concern to highway authorities. Lack of adequate friction between the tire and road surface can lead to traffic accidents, especially in wet weather [1]. The existing skid resistance measuring methods can be divided into low speed and high speed methods. The common low speed testing instruments include the British Pendulum tester (BPT) and the Dynamic Friction Tester (DFT). For high speed testing equipment, there are relatively more choices, such as lockedwheel skid tester, Scrim, Mu-Meter, grip tester and so on [24]. Both low speed skid resistance and high speed skid resistance are important properties for comprehensive

S. Han is with the School of Highway, Chang'an University, 710064, Xi'an, China (e-mail: hyram hs@chd.edu.cn)

T.F. Fwa is with the School of Highway, Chang'an University, 710064, $\mathrm{Xi}$ 'an, China.

M. Liu is with the School of Highway, Chang'an University, 710064, Xi'an, China. evaluation of pavement skid resistance, but in actual engineering, only high-speed skid resistance of pavement is often measured. Low speed skid resistance is also the critical factor for the in-depth analysis of insufficient skid resistance of pavement, and the necessary information for making corrective maintenance or repair measures. This paper reviews the current low speed skid resistance test methods, pointed out their limitations, and emphasizes the need for a better test method. The Walking Friction Tester (WFT) developed by Chang'an University was used to evaluate the low-speed skid resistance of the pavement reliably and accurately.

\section{Mechanism of Low Speed and High SpeEd SKID RESISTANCE}

Skid resistance is composed of adhesion and hysteresis, the former is related to the microtexture of the aggregates with a wavelength of $1 \mu \mathrm{m} \sim 0.5 \mathrm{~mm}$, and has a certain control effect on the low-speed skid resistance. The latter is related to the overall structure of a pavement with a wavelength of $0.5 \mathrm{~mm} \sim 50 \mathrm{~mm}$, which affects the high-speed skid resistance of the pavement [5-7].

The three-zone concept of Moore's law, namely the front "squeezed-film zone", the middle "transition zone" and the "traction area" in the rear, is used to explain the change of the skid resistance with the velocity. When the tire sliding speed is high, the effective skid resistance decreases with the decrease of the "traction zone". On the other hand, with the slower speed of the tire, the larger the contacted area of the tire surface is, the greater the "traction area" becomes, and the friction between tire surface and pavement increases [8].

\section{REVIEW OF BPT AND DFT}

BPT and DFT have been widely used in laboratory and field tests. However, previous studies have found that BPT and DFT have many limitations in the test of skid resistance:

(1) BPT is a pendulum impact test machine. Its rectangular rubber slider impacted the test surface at an angle during the test. DFT measures the friction force by the circular motion of the rotary rubber pad. The contact modes and mechanisms of the two devices are different from those of the vehicle tire and pavement surface. This makes the test result of the sliding mode unreliable when testing on coarse texture road surface $[9,10]$. 
(2) On the pavement with grooves, BPT must be carefully placed to avoid slider slid into the groove. In the case of DFT, the rubber slider would be jammed with the grooves easily due to its small size during the test, resulting in the displacement gauge failure. In addition, its main problem is its circular motion test mode. It is unable to test the directional skid resistance performance of grooved pavement [4].

(3) BPT and DFT are devices used to measure the skid resistance in the field. The test results cannot fully evaluate the skid resistance of the whole road surface. Both BPT and DFT will take a long time to meet the requirements of the test specification.

(4) It may be difficult to use BPT and DFT to measure the skid resistance of the pavement on the slope or uneven pavement in the aspect of instrument levelling [9].

\section{DESCRIPTION OF WFT}

The questionnaire was prepared and issued by the surveyors A picture of WFT is shown in Figure 1. WFT is equipped with speed sensors and torque sensors to measure testing speed and record wheel torque respectively. According to the measured torque, the WFT test results (Walking Friction Coefficient, WFC) were calculated by equation 1 .

$$
W F T=\frac{M}{R \times P}
$$

where $\mathrm{M}$ is the measured torque, $\mathrm{R}$ is the radius test wheel, and $\mathrm{P}$ is the vertical load on the test wheel. Parameters of the WFT are shown in Table 1.

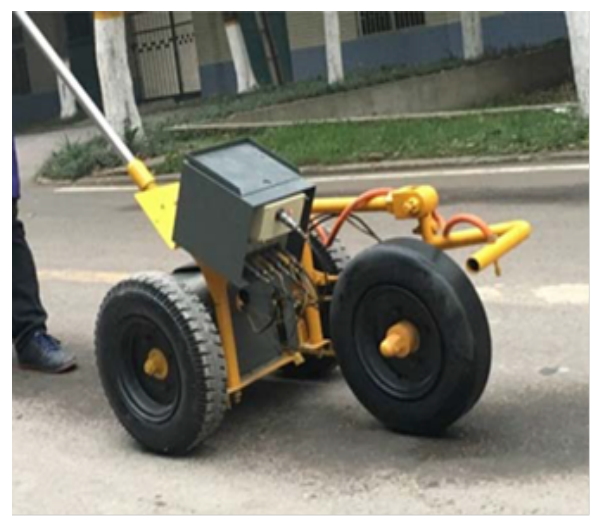

Fig. 1. The appearance of WFT.

TABLE I

\begin{tabular}{c|c}
\multicolumn{2}{c}{ PARAMETERS OF WFT } \\
\hline Technical specification & value \\
\hline Length $(\mathrm{mm})$ & 980 \\
\hline Width $(\mathrm{mm})$ & 640 \\
\hline Height $(\mathrm{mm})$ & 700 \\
\hline Weight $(\mathrm{kg})$ & 60 \\
\hline Speed $(\mathrm{m} / \mathrm{min})$ & 15 to 60 \\
\hline Test wheel texture & Smooth \\
\hline Test wheel radius $(\mathrm{mm})$ & 200 \\
\hline Size & $4.00-8$ \\
\hline Vertical load $(\mathrm{N})$ & 196 \\
\hline Air pressure $(\mathrm{MPa})$ & 0.1 \\
\hline Slip ratio & $0 \%, \quad 10 \%, 20 \%, 30 \%, \quad 100 \%$ \\
\hline
\end{tabular}

\begin{tabular}{c|c}
\hline Rear wheel texture & pattern \\
\hline Rear wheel radius $(\mathrm{mm})$ & 200 \\
\hline $\begin{array}{c}\text { Water spray Capacity } \\
(\mathrm{ml} / \mathrm{s})\end{array}$ & 45 \\
\hline
\end{tabular}

\section{COMPARISON OF BPT, DFT AND WFT}

\section{A. Reliability and accuracy of friction measurement}

The reliability of BPT, DFT and WFT was evaluated with the variation coefficient (CV) measured in 30 measurements. As shown in Table II, the CV values of the WFT test results were obviously smaller, when compared with those of the DFT test results. On AC13, PCC0 and PCC3(L2) specimens, the coefficients of variation of BPN was slightly smaller than those of WFC, while the remaining 13 cases produced larger $\mathrm{CV}$ than WFC.

In the case of PC16 and PCC6(T), its high CV value clearly proves the problem of BPT in measuring the surface friction of coarse texture. And the CV of BPN increased with the increase of groove width. However, the WFC had slighter CV of $2.53 \%, 3.09 \%$ and $3.41 \%$ respectively for the grooved surface of $3 \mathrm{~mm}, 4 \mathrm{~mm}$ and $6 \mathrm{~mm}$ in width. DFT cannot be used on coarse or grooved surfaces because the displacement gauge would be failure for great impact resistance when the three small high-speed rubbers are in contact with the surface of the specimens.

The BPN and WFC of 10 test cases were positively correlated with the correlation coefficient of 0.78 . The DF20 and WFC of 5 test cases had good correlation coefficient of 0.93 . These indicate that the three devices are generally consistent in distinguishing surfaces with different low-speed friction characteristics. But the correlation coefficient between BPN and WFC was significantly lower than that of DF20 and WFC because BPNs included measuring values on coarse pavement.

It can be seen from Table II that there are obvious problems with the BPN value of the grooved surface of PCC3(T), PCC4(T), PCC6(T). The results show that when the rubber pavement contact area is larger, the low speed friction is higher $[9,11]$. The friction values of WFC described this trend correctly, namely, PCC3T > PCC4T4) $>$ PCC6TN. Due to the groove edge interference in BPT testing, the BPN readings were in the opposite order. Based on this observation and the fact that the friction mechanism of WFT is closer to practical skid resistance than that of BPT, it is concluded that WFT test is more suitable for low-speed friction measurement of different surfaces. 
TABLE II

SUMMARY OF SKID RESISTANCE TEST RESULTS

\begin{tabular}{llllllllll}
\hline $\begin{array}{l}\text { Slab } \\
\text { Specimen } \\
\text { Code** }\end{array}$ & \multicolumn{2}{l}{ Average Test Value } & \multicolumn{3}{c}{ Standard Deviation } & \multicolumn{3}{c}{ Coefficient of Variation CV (\%) } \\
\cline { 2 - 9 } & BPN* $^{*}$ & $\mathrm{DF}_{20} *$ & $\mathrm{WFC}^{*}$ & $\mathrm{BPN}^{*}$ & $\mathrm{DF}_{20} *$ & $\mathrm{WFC}^{*}$ & $\mathrm{BPN}^{*}$ & $\mathrm{DF}_{20} *$ & $\mathrm{WFC}^{*}$ \\
\hline AC13 & 64.9 & 0.7590 & 0.746 & 0.9625 & 0.0617 & 0.0133 & 1.48 & 8.14 & 1.78 \\
SMA13 & 64.7 & 0.5721 & 0.739 & 2.3638 & 0.0438 & 0.0219 & 3.66 & 7.67 & 2.97 \\
PA16 & 62.5 & 0.5447 & 0.665 & 2.2143 & 0.0379 & 0.0211 & 3.54 & 6.97 & 3.18 \\
PA20 & 65.9 & 0.5234 & 0.693 & 2.1089 & 0.0405 & 0.0209 & 3.20 & 7.74 & 3.01 \\
PC16 & 63.0 & - & 0.741 & 3.1005 & - & 0.0215 & 4.92 & - & 2.89 \\
EACC & 71.5 & - & 0.701 & 2.3960 & - & 0.0208 & 3.35 & - & 2.97 \\
PCC0 & 80.2 & 0.8751 & 0.800 & 1.1198 & 0.0496 & 0.0130 & 1.40 & 5.68 & 1.62 \\
PCC3(T) & 80.2 & - & 0.837 & 2.3751 & - & 0.0212 & 2.96 & - & 2.53 \\
PCC3(L1) & 74.6 & - & 0.815 & 2.0151 & - & 0.0211 & 2.70 & - & 2.59 \\
PCC3(L2) & 74.4 & - & 0.812 & 1.5187 & - & 0.0185 & 2.04 & - & 2.27 \\
PCC4(T) & 83.5 & - & 0.818 & 3.0478 & - & 0.0252 & 3.65 & - & 3.09 \\
PCC4(L1) & 77.7 & - & 0.806 & 2.3173 & - & 0.0225 & 2.98 & - & 2.79 \\
PCC4(L2) & 77.4 & - & 0.803 & 1.6449 & - & 0.0162 & 2.12 & - & 2.02 \\
PCC6(T) & 84.8 & - & 0.786 & 7.3616 & - & 0.0268 & 8.69 & - & 3.41 \\
PCC6(L1) & 63.4 & - & 0.727 & 1.3898 & - & 0.0153 & 2.19 & - & 2.11 \\
PCC6(L2) & 64.7 & - & 0.736 & 1.3010 & - & 0.0122 & 2.01 & - & 1.66 \\
\hline
\end{tabular}

Notes:

* $\mathrm{BPN}=$ British pendulum number;

DF20 $=$ Friction coefficient measured by Dynamic Friction Tester at $20 \mathrm{~km} / \mathrm{h} ; \mathrm{WFC}=$ Friction coefficient measured by Walking Friction Tester.

** $\mathrm{AC} 13=$ dense-graded asphalt mixture specimen with the maximum aggregate size of $13 \mathrm{~mm}$;

SMA13= stone matrix asphalt mixture specimen with the maximum aggregate size of $13 \mathrm{~mm}$;

PA16= porous asphalt mixture specimen with the maximum aggregate size of $16 \mathrm{~mm}$;

PA20 $=$ porous asphalt mixture specimen with the maximum aggregate size of $20 \mathrm{~mm}$;

$\mathrm{PC} 16=$ porous cement concrete specimen with the maximum aggregate size of $16 \mathrm{~mm}$;

PCC0, PCC3, PCC4 and PCC6= Portland cement concrete specimen grooved with gap of $0 \mathrm{~mm}, 3 \mathrm{~mm}, 4 \mathrm{~mm}$ and $6 \mathrm{~mm}$ respectively;

$(\mathrm{T})=$ Friction measured in transverse direction (i.e. perpendicular to grooves);

$(\mathrm{L} 1)=$ Friction measured in longitudinal direction along groove top surface centre;

(L2) $=$ Friction measured in longitudinal direction along groove bottom centre

\section{B. Testing time}

WFT has significant advantages of providing continuous friction within the entire testing range. But the BPT and DFT can only provide point measurements, which cannot fully reflect the changing trend of friction over the whole road because it is subject to influence the selection of measurement pots.

Another advantage of WFT is the efficiency of testing, particularly in field. As shown in Table III, the testing time of WFT in the laboratory was less than the testing time of BPT and DFT. In field measurement, test time could be saved greatly for WFT high efficiency.
TABLE III

TEST TIME OF BPT, DFT, WFT

\begin{tabular}{c|c|c|c}
\hline \multirow{2}{*}{$\begin{array}{c}\text { Slab Specimen } \\
\text { Code** }\end{array}$} & \multicolumn{3}{|c}{ testing time(minute) } \\
\cline { 2 - 4 } & BPT* $^{*}$ & DF $20^{*}$ & WFT* \\
\hline AC13 & 7.30 & 6.30 & 5.18 \\
SMA13 & 6.93 & 6.50 & 4.88 \\
PA16 & 6.18 & 6.13 & 4.81 \\
PA20 & 7.00 & 6.50 & 4.88 \\
PC16 & 7.95 & - & 4.50 \\
EACC & 7.31 & - & 4.62 \\
PCC0 & 7.13 & $6.30-$ & 4.95 \\
PCC3 & 7.50 & - & 4.55 \\
PCC4 & 6.97 & - & 4.30 \\
NOCC6 & 6.95 & - & 4.41 \\
In field & 46.00 & - & 2.00 \\
\hline
\end{tabular}

\section{Effect of testing speed}

Walking speed tests of 10 test cases were conducted, test results of which were shown in Table 4 . The study on the testing speed range included the most operator's normal walking speed. The conclusion of statistical hypothesis test is that, for all the 10 patients, the testing speed had little effect on the WFC at the statistical significance level of $95 \%$. Therefore, it can be concluded that the measurement of WFT is not affected by the testing speed in the range of walking speed of ordinary people. 
TABLE IV

TEST RESUlt OF WFT WITH DIFFERENT TEST SPEED

\begin{tabular}{c|c|c|c|c}
\hline \multirow{2}{*}{$\begin{array}{c}\text { Slab } \\
\text { Specimen } \\
\text { Code** }\end{array}$} & \multicolumn{4}{|c}{ WFT } \\
\cline { 2 - 5 } & $15(\mathrm{~m} / \mathrm{min})$ & $30(\mathrm{~m} / \mathrm{min})$ & $45(\mathrm{~m} / \mathrm{min})$ & $60(\mathrm{~m} / \mathrm{min})$ \\
\hline AC13 & 0.757 & 0.749 & 0.756 & 0.744 \\
SMA13 & 0.748 & 0.747 & 0.737 & 0.730 \\
PA16 & 0.703 & 0.705 & 0.690 & 0.695 \\
PA20 & 0.717 & 0.707 & 0.713 & 0.701 \\
PC16 & 0.741 & 0.725 & 0.730 & 0.714 \\
EACC & 0.731 & 0.721 & 0.713 & 0.708 \\
PCC0 & 0.826 & 0.828 & 0.833 & 0.814 \\
PCC3 & 0.849 & 0.845 & 0.850 & 0.828 \\
PCC4 & 0.822 & 0.819 & 0.810 & 0.805 \\
PCC5 & 0.806 & 0.790 & 0.796 & 0.784 \\
\hline
\end{tabular}

\section{CONCLUSION}

This study emphasized the importance of low speed skid resistance and introduced a new low-speed skid resistance test method of WFT. Compared with the commonly used BPT and DFT devices, the stability of WFC was better than that of BPN and DF20, especially in coarse textured or grooved pavement. The three devices are consistent in measuring the surface of different low-speed friction characteristics. However, BPN is not reliable, and DFT is not suitable for groove pavement. The opposite order of friction test results existed on different groove width specimens for BPT, compare with WFT measurements. Based on this observation, and the fact that the friction mechanism of WFT is closer to the vehicle riding mode than that of BPT, it is considered that the WFT arrangement is more suitable for low-speed friction measurements on different surfaces. Besides, WFT can provide continuous friction measurement and save a lot of testing time. In the range of walking speed of ordinary people, the measured results of WFT were not affected by testing speed. From the results, it is concluded that WFT can be used as a substitute for BPT when measuring the low-speed friction characteristics of pavement in laboratory or field.

The authors gratefully acknowledge financial support from National Natural Science Foundation of China (No. 51578076).

\section{REFERENCES}

[1] D. L. Ivey, L. I. Griffin, J. R. Lock, and D. L. Bullard, "Texas skid initiated accident reduction," Research Report 910-1F, Texas Transportation institute, 1992.

[2] S. Najafi, G. W. Flintsch, and K. K. Mcghee, "Assessment of operational characteristics of continuous friction measuring equipment (CFME)," International Journal of Pavement Eng., Vol. 14, No. 8, 706-714, 2013.

[3] X. Dong, P.S. Zhang, and X.Q. Ding, "The Texture Construction and Skid Resistance Measurement of Asphalt Mixture Pavement," Highw., Vol. 14, pp.14-19, 2011.

[4] M. Forde, R. M. Birse, and D.Fraser, "An Assessment of British Pendulum Methods of Skid Resistance Evaluation Using
Schonfeld's Photo-interpretation Method," The 8th Conf of the Australian Road Research Board, Perth, Australia, vol.8, pp.2941, 1976.

[5] U. Sandburg, "Influence of Road Surface Texture on Traffic Characteristics Related to Environment, Economy, and Safety: A State-of-the-Art Study Regarding Measures and Measuring Methods," VTI Report 53A-1997, Swedish National Road Administration, Borlange, Sweden ,1998.

[6] J.J. Henry, "Evaluation of Pavement Friction Characteristics-A Synthesis of Highway Practice," NCHRP Synthesis 291, Transportation Research Board, 2000.

[7] H.W. Kummer, "Unified Theory of Rubber and Tire Friction," PA State University, College of Engineering, University Park, PA, 1966.

[8] D.F.Moore, "Prediction of skid resistance gradient and drainage characteristics for pavements," Highway Research Records, 131, pp. 181-203, 1966.

[9] Y.P.K. Lee, T.F. Fwa , and Y.S Choo, "Effect of Pavement Surface Texture on British Pendulum Test," Journal Eastern Asia Soc. Transp. Stud., Vol. 6, pp. 1247-1257, 2005.

[10] G.F. Salt, "Research on Skid Resistance at the Transport and Road Research Laboratory (1927-1977)," Transportation Research Record 622, Washington, DC, 1977.

[11] T.F. Fwa, Y.S. Choo and Y. Liu, "Effect of aggregate spacing on skid resistance of asphalt pavement," Journal Transp. Eng., 129(4), pp.420-426, 2003. 